\title{
A new path for humanistic medicine
}

\author{
Juliette Ferry-Danini \\ Université Paris-Sorbonne \\ "Sciences, Normes, Décision"
}

\begin{abstract}
According to some recent approaches in the philosophy of medicine, biomedicine should be replaced or completed by a humanistic medical model. Two humanistic approaches, narrative medicine and the phenomenology of medicine, have notably grown popular in the last decades. This paper first suggests that these humanistic criticisms of biomedicine are insufficient. A central problem is that both approaches seem to give a straw man definition of biomedicine. Second, I argue that the subsequent definition of humanism found in their approaches is problematically reduced to a compassionate or psychological approach. My main claim is that humanism cannot only be looked for in the patient-physician relationship and that a broad definition of medicine should help revisit humanism. With this end in view, I defend what I call an outcomes-oriented approach to humanistic medicine, where humanism is set upon the capacity for a health system to produce good health outcomes.
\end{abstract}

\section{Keywords}

Humanistic medicine - Narrative medicine - Phenomenology - Biomedicine - Health systems French cancer plans

\section{Where should we look for humanism?}

Narrative medicine [1-3] and the phenomenology of medicine [4-12] are two popular humanistic approaches in the philosophy of medicine. They argue for what they call a humanistic medicine, a medicine that "heals" as well as it "cures" patients, and where compassion and empathy are key 
features of the patient-physician relationship. Their target is what they call the biomedical model $[2,9,10]$, which is argued to be at the root of a practice of medicine that is not as humane as it could be. Although humanistic goals are certainly honorable, I am not satisfied with the main approaches within the humanistic medicine literature - most specifically narrative medicine and the phenomenology of medicine -, and I wish to introduce instead a new approach.

First, both narrative medicine and the phenomenology of medicine face problems regarding their given definition of what they call the biomedical model. Although they follow distinct strategies to criticize the biomedical model, they fail to give a credible account of such a model. Both approaches notably criticize what amounts to caricatures. This is the first reason for wanting to improve the current humanistic approach.

Accordingly, I will give a sense of what humanism currently means in the literature. As I will argue, the version of humanism endorsed by narrative medicine and the phenomenology of medicine fails to go beyond a compassionate and psychological approach. Thus, by identifying key features of compassionate humanism such as empathy, emotions, and psychological intersubjectivity, I will argue that the compassionate approach is too weak, notably because it relies on an unnecessarily narrow definition of medicine. Other definitions of medicine and humanism should help to improve humanistic medicine.

The question I address is simple: where should we look for humanism? What exactly is and should be humanistic in medicine? I will argue that humanism should not be studied only at the level of clinical encounter but also at the level of health systems. In other words, the topic of humanism should be placed upon a broader picture of medicine, which includes health systems and public health. Doing so enables us to go beyond a merely compassionate and intersubjective approach. Concrete examples from the current French health system will be given to illustrate in what sense public health and/or a health policy may be humanistic. I will then turn to defend what I call an 
outcomes-oriented approach to humanistic medicine which I argue to enable the expansion of the meaning of humanism beyond its current use.

\section{Humanistic approaches to medicine: an overview}

Ten years ago, James Marcum [13] compiled a series of approaches in the philosophy of medicine fitting the label "humanistic medicine" or "humanistic approach to medicine." Behind these labels, we find the XIX's century old opposition between humanism and scientism and the recent loss of faith in biomedicine and the biomedical model:

Why should modern medicine provide such competent technical care and yet fail to provide the humane care patients also need? [13, p. 393]

Many voices have indeed raised concerns, in popular media and elsewhere, against what is sometimes perceived as inhumane care. If the philosophy of medicine has mainly concerned itself with defining the concepts of health and diseases, it has less often been concerned with the larger topic of the practice of healthcare, and what it ought or ought not to be. Marcum argues that the philosophy of medicine should now turn to study the basis of our medical practices, by studying topics such as emotions in clinical practice, intersubjectivity and the individual experience of illness. For lack of a better word, as Marcum confesses, "humanistic" is meant to designate those approaches that focus on medicine as a human interaction and emphasize the subjectivity of the patient. As noted by Solomon, they sometimes claim that medicine should "care for the whole person" rather than "treat the disease" [14, p. 11]. Many authors share this belief $[2,3,6,17-19]{ }^{1}$

The emphasis on the subjective experience of the patient is one of the key claims of proponents of humanistic medicine. Havi Carel [6] has for instance argued that the current debate over the definitions of health and disease problematically never take into account the first-person perspective of those concepts. According to her, neither a naturalistic account that focuses on disease as a biological dysfunction nor a normativist account that focuses on how society understands

\footnotetext{
${ }^{1}$ Quoted by [14]
} 
disease can give a voice to the individual patient $[6$, p. 9, p. 13]. In putting forward the importance of the subjective experience, humanistic approaches intentionally go beyond the question of the definition of the concepts of health and disease to tackle instead the conceptual foundations of our medical practice. On this, they seem to draw inspiration from authors like George Engel [17] and George Khushf [20] (although most of the time only the former is mentioned). Engel and Khushf are two of several authors who noticed the problematic nature of the debate around the concepts of health and disease. Khushf has recently argued that the only way out of the loop of the debate is to study the theoretical framework we have presupposed to carry out our conceptual analysis. He argues that in doing so, one would notably realize that both naturalists and normativists share a common biomedical model. According to him, to reframe the debate and to study the theoretical models that underlie our concepts should prove more successful than to continue a never-ending cycle of conceptual analysis. ${ }^{2}$ Humanistic medicine proponents seem to have followed Engel and Khushf's impulses into a broad criticism of biomedicine and the biomedical model. However this rejection of the biomedical model is often claimed not to be radical: most proponents of humanistic approaches claim they only wish to complement it, not to replace it $[6, p .11]$. This avowal remains ambiguous: for instance, how can one accuse the biomedical model of being dualistic and reductionist about illness and disease and at the same time only wish to complement it? Keeping this issue in mind, does the humanistic criticism of the biomedical model prove successful? This will be answered shortly.

It should briefly be mentioned that despite similarities, humanistic medicine comes in several forms and relies on different arguments. Besides narrative medicine and the phenomenology of medicine, other approaches include virtue ethics [22], other methods to understand the illness experience, for instance, hermeneutics $[4,23,24]$, and works on the value of empathy, and emotion in healthcare [18]. Overall, humanistic medicine agrees that the patient should be understood as living in a specific social and cultural environment, while the physician's practice should correspondingly be

\footnotetext{
${ }^{2}$ See also [21] for a detailed criticism of the use of conceptual analysis in the philosophy of medicine.
} 
understood as involving cultural and emotional skills on top of her scientific competences. In Marcum's own words, humanistic medicine refers to "a variety of humane or humanistic models (...) in which the patient's human dimension is reinstated into the patient-physician relationship" $[22, p$. v].

The aim of this paragraph was to give a sense of the broad picture of humanistic approaches in philosophy of medicine. In what follows, however, I will restrict my arguments and my criticism to narrative medicine and phenomenology of medicine only. I will focus on one key argument in those approaches - their criticism of biomedicine. Both approaches have gained popularity in the field and feature in the recent handbooks that have been published $[25,26]$.

\section{A humanistic consensus with problematic targets}

The apparent humanistic consensus against the biomedical model should not conceal that each humanistic approach usually has a different target in mind. Since their target is different, as I will now show, it is at best misleading of humanistic proponents to give the impression of a common banner against biomedicine. The result is confusion over the weight and the pertinence of the consensus against the biomedical model. In what follows, I will deal into further detail with the criticisms of biomedicine as it is brought up by narrative medicine and the phenomenology of medicine. I briefly argue that the two criticisms hit it off the mark.

\subsection{Narrative medicine and science}

For narrative medicine, the problem with the biomedical model is that it is a scientific model. Kathryn Montgomery Hunter claims, for instance, that

\footnotetext{
"[d]espite its success, medicine's identification as a science has had adverse effects (...). It encourages physicians and patients alike to focus narrowly on the diagnosis of disease rather than attend to (...), the care of the person who is ill (...)." [3, p. xix].
}

Meanwhile, Rita Charon argues that biomedicine - which she also calls "scientific medicine" [2, p. 3], "is incapable of saying something about specific individuals or meaningful situations" [2, p. 9]. She 
also argues that "[t]he price for a technologically sophisticated medicine" seems to be a healthcare, "consumed with the scientific elements" of biomedicine, at the expanse of human experiences such as pain and suffering $[2$, p. 6]. Accordingly, proponents of narrative medicine generally argue that a new approach should be introduced in order to deal with what goes beyond the scope of what is purely scientific and biological in medicine. ${ }^{3}$ One question remains: if science has such adverse effects on patients, how can complementing it with a narrative approach can fix those effects?

As many recognize in the philosophy of medicine (see for instance [14, p. 12]), it could be that different epistemological approaches are indeed useful, each in their own terms for medicine and its practice. This position seems to satisfy methodological pluralism, a view in the philosophy of science according to which there is more than one scientific method [28-30]. According to proponents of narrative medicine however, the difference is stronger. They argue that medicine is an art (as opposed to and in addition to a science), which entails listening to and understanding the patients' stories of illness. Their main claim is that narrative theory should enable doctors to understand their patients' stories and consequently make them better healers. For instance, Charon claims that narrative medicine will "lead to more humane, more ethical, and perhaps more effective care" [2, $p$. 7]. ${ }^{4}$

The first problem is that it seems rather difficult to argue that today's medicine (in rich countries) - albeit scientific - is only concerned about the physical bodies of patients. What about social workers or physician-led prevention? As Mäel Lemoine [32] has argued, it seems difficult even to distinguish a purely scientific medicine from its normative counterparts. Rita Charon describes science as a value-neutral objective and theoretical undertaking that is fundamentally incompatible with subjective experience - that is, in her own view, incompatible with psychological states, values, and individuality [2, p. 6-7]. What about psychiatry and psychology? They both deal with

\footnotetext{
${ }^{3}$ The reduction of science to biology alone is often found in the narrative medicine literature. Science is described as only capable of dealing with the biological aspect of disease.

${ }^{4}$ By contrast, [31] merely claim that it will lead to more "humane discourses in the context of health services research" [31, p. 555].
} 
psychological data, behaviors and subjective experiences. Even more problematic, it is important to emphasize that an up-to-date philosophy of science, such as exemplified by John Dupré's pluralism [33] or Helen Longino's [28,29] and Miriam Solomon's feminist and empiricist works [14,34], gives a very different image of science. Since the works of Thomas Kuhn $[35,36]$, science is no longer understood as a value-free and objective knowledge but as a messy normative activity that nonetheless retains its epistemological legitimacy. Claiming that the "coldness" $[2$, p. 10] of the practice of science is incompatible with anything social, normative or psychological presumes a traditional logical positivist (or logical empiricist) philosophy of science that is worryingly outdated. Rita Charon, for instance, seems to take for granted that stories and narration are specific to an art or a practice and by nature antithetical to science. However, as Miriam Solomon has argued, narration telling stories - is "quite common in science" [14, p. 179]. For instance, most theories of evolution from the end of the 19th century make great use of stories where narrative and progress (or lack of progress) are very important. As Solomon argues, stories are often used, so to speak, to discover and think about causal connections and are thus unsurprisingly found in science $[14, p .179]$. The stereotypical pictures of biomedicine and science found in the criticism voiced by narrative medicine is closer to a straw man than anything else, which in turn seems to cast doubts on the weight of its main claim on humanism. ${ }^{5}$

\subsection{Phenomenology and philosophical naturalism}

Let's turn now to the case of the phenomenology of medicine. The target of its proponents is not, strictly speaking, science but instead a philosophical position - naturalism, to which they oppose the stories and descriptions of the first-person experience of illness.

I found phenomenology - the description of lived experience - to be the most helpful approach to augmenting the naturalistic account of illness. [6, p. 10]

\footnotetext{
${ }^{5}$ It should made be clear however, that this critique doesn't aim to cast doubt on the whole narrative medicine enterprise: extremely well done and interesting analysis of patients' stories exist (see for instance [31]). My target is merely the key theoretical basis of the narrative approach: criticizing biomedicine. It should also be noted that narrative works can do without making specific claims against biomedicine or in favor of humanism, although they often do.
} 
Philosophical naturalism, ${ }^{6}$ as it is commonly called, comes in different forms, whether it is intended to be a metaphysical or an epistemological thesis. ${ }^{7}$ Metaphysical naturalism is a thesis about the ontology of the world: only what science can account for exists. On the other hand, epistemological naturalism states that science has an epistemological priority in the knowing of the world but doesn't claim anything about the reality or the existence of that world. As argued by Jonathan Sholl [39], in the philosophy of medicine, metaphysical naturalism could correspond to a thesis about the existence of diseases while epistemological naturalism would amount to a thesis about the demarcation between health and disease [39, p. 295-6], or more simply to a thesis on the understanding or explanation of disease. The proponents of the phenomenology of medicine do not however refer to such a distinction, and sometimes seem to confuse the two theses. For instance, in the following quote, Toombs seems to equate the question of the definition of the concept of disease with that of the existence of disease: ${ }^{8}$

The traditional biomedical model focuses on the disease process. Illness is conceptualized as an objective, abstract entity, in some way separated from the one who is ill. [9, p. 235]

She also takes upon herself to criticize what she calls the "the prevailing reductionist Cartesian paradigm (...)" [10, 201]. Very often (although not always) Carel, Toombs but also Fredrick Svenaeus describe naturalism in terms of a reductive physicalism, i.e. a radical form of metaphysical naturalism which states that only the things that physics (in our case, biology) can account for exist. For instance, Fredrick Svenaeus writes the following:

For the standard doctor there will consequently be no illness, no medical suffering so to say, without a disease. [40, p. 233]

In other words, according to Svenaeus, in the biomedical model, there is no such thing as an illness without a biologically identified cause. On top of being a slippery claim (do physicians really think biological dysfunctions are the end of the stories of illness?), this type of reductive physicalism, although it exists elsewhere in philosophy, is not supported by any author in the philosophy of

\footnotetext{
6 "Bald naturalism" is also found, see [38].

7 "Ontological" and "epistemic" are also found.

${ }^{8}$ Although I agree that it is not clear, see below.
} 
medicine. For instance, even Christopher Boorse [41], the main proponent of naturalism in medicine, famously does not reduce illness to disease - his most important conceptual move is to distinguish them - he does not support reductive physicalism. Élodie Giroux has, for instance, described Boorse's approach as a non-reductive naturalism [42]. It is misleading to argue, as Carel and Toombs do, that naturalism necessarily reduces illness to biological dysfunctions. As Sholl argues, naturalists would all agree (as does Boorse) about complementing their naturalist approach with first-person descriptions of illness [39, p. 397]. This is why I agree with Sholl that the charge of the phenomenology of medicine against naturalism is unfair and close to a straw man [39, p. 395]. Reductive physicalism (Carel and Svenaeus) or reductive Cartesianism (Toombs) is not something that is defended in the philosophy of medicine and there is not any reason to think that it is somehow unconsciously enforced by health systems and physicians. ${ }^{9}$

Overall the humanistic consensus against the biomedical model loses its force as soon as we realize that no clear definition of the biomedical model has been given and that there is in fact no agreement upon its criticism. What is the target of this humanistic consensus: naturalism or science or both? If the target is naturalism, which and whose naturalism? If the target is science, to criticize an old-fashioned positivist view of science will not be enough. I argued that current criticisms of science and naturalism found in narrative medicine and the phenomenology of medicine are problematic if not simply straw man arguments. The definitions of science as objective, value-free knowledge and naturalism as reductive physicalism are close to caricatures. Furthermore, it is not clear how humanistic proponents can pose such strong criticisms of science and naturalism and at the same time only wish to complement them. Although my criticism does not claim to be exhaustive, it casts some doubts about the consensus of humanistic approaches against the biomedical model. As I will show, it is unnecessary to pit science against art and to target something as ambiguous as the biomedical model to defend a humanistic approach in medicine.

\footnotetext{
${ }^{9}$ It should be noted that my argument here stands only against the criticism of biomedicine found in the current approaches in the phenomenology of medicine. Phenomenology of medicine encompasses a complex and rich bundle of claims which description and assessment are out of the scope of this paper.
} 


\section{How humanistic is humanistic medicine? The current compassionate approach}

As James Marcum has acknowledged [22, p. v], "humanistic" and "humane" - but also "human" and even "humanness" [10, p. 202] - are usually never distinguished in the humanistic literature. While "human" may refer to the human condition or the intrinsically social human life, "humane" denotes the concern for alleviating suffering, and emotions such as compassion or kindness. "Humanistic" is polysemous: it can refer to humanism, a philosophy that centers on humans, their dignity, values and freedom but it also can mean something closer to "humanitarian" and "humane", denoting a concern for human welfare and compassion. ${ }^{10}$ The use of such straightforward definitions has yet to be found in the current literature. It is possible, however, to extrapolate and draw a general picture of what is generally meant by those concepts. Three imperatives usefully describe to what degree humanistic approaches are humanistic. Those imperatives correspond to each prominent claim put forward by humanistic proponents in order to humanize medicine and its practice.

\subsection{Empathy and emotions}

What will humanize medicine? According to most authors, the first imperative is that emotions of both patients and physicians play an important role in medicine and its practice. A "humane physician" [13, p. 396] should try her best to empathize with her patient and understand the patient's psychological and emotional needs. Only then will she be able to properly understand the stories and the suffering of her patients. Charon writes for instance that what people seek is "a form of healthcare that recognizes suffering, provides comfort, and honors the stories of illness" $[2, p . i x]$. Furthermore Charon, like Jodi Halpern [18], argues that empathy - Halpern calls it emotional reasoning - has an epistemological virtue on top of its social and emotional importance. Contrary to the neutral physician, the empathetic practitioner will be able to heal and treat her patient better. Charon and Halpern give extensive examples from their own practices as physicians and psychiatrists.

\footnotetext{
${ }^{10}$ I discard two other meanings: humanism as in the study of humanities, and humanism as in the intellectual movement during the Renaissance. Although less relevant, these two connotations are often implicitly present in the background, especially, for instance, in the case of narrative medicine and other types of medical humanities. See [19, 31-32].
} 
If the exact nature of empathy is ambiguous - is it something like an emotion (Charon) or more like a reasoning process in its own right (Halpern)? - authors agree upon the importance of patients' emotions.

\subsection{Patients beyond bodies}

The second imperative follows from the first one: in humanistic medicine, patients should not be reduced to their biological bodies but also regarded as psychological beings. Carel writes that beyond their bodies, patients are "psychological, cultural, social, cognitive, emotional, existential, and temporal beings" [7, p. 11], hence the extensive use of the concept of the "person" found in the literature [see especially 19]. ${ }^{11}$ It is important to emphasize that for humanistic proponents, insisting on the "subjective experience" of the patient means insisting on her psychological state. For humanistic proponents, the subjective and the psychological refer to the same thing. ${ }^{12}$ The psychological is in turn often conflated with the cultural, social, cognitive, and so on, i.e. with every non-physical or non-biological human aspect. Authors criticize the dehumanizing face of biomedicine, a model under which, according to them, patients are taken only as physical bodies, and their emotional and psychological - as well as existential $\left.\right|^{13}$ - needs are not met. A less central imperative is the idea that what should matter in medicine is each individual particular patient per se and not in general (the insistence on the individual is recurrent especially in the literature of narrative medicine, but echoes are found in the phenomenology of medicine). ${ }^{14}$ It is of course the particular psychological individual that is valued, not his particular physical body. In fact, it seems here that concepts such as individuality, subjectivity and particularity are all somehow reduced by humanistic proponents to what has to do with psychological or mental states. Of course, the problem is that

\footnotetext{
${ }^{11}$ See also Carel "The complaint that seems to appear near-universal in this context is: why am I not treated as a person?" [6, p. 54]

${ }^{12}$ Much of psychology, however, is not focused on the subjective experience. See below.

${ }^{13}$ Sulmasy [19] would also add the spiritual needs.

${ }^{14}$ Solomon sees in it the cultural importance of individuality in the Anglo-Saxon world, especially in the United States [14].
} 
much of psychology doesn't focus on the subjective experience (nor does it necessarily focus on particular individuals). ${ }^{15}$

\subsection{The patient-physician relationship}

The third and final imperative for humanistic medicine consists of the definition of medicine being fundamentally an intersubjective practice. The medical encounter is understood as primarily characterized by the encounter between two subjects - the patient and her physician. The "humane" face of medicine, as humanistic proponents call it - let's say "humanism" - should therefore, by definition, be sought in the patient-physician relationship. As Solomon has noticed, it seems that according to humanistic proponents, humanities (in this case, phenomenology and narrative art) are by definition more humanistic than science [14, p. 193] and should thus be preferred for the task of humanizing the medical relationship.

In brief, humanism for humanistic medicine seems to mean the following: given that both physicians and patients are individual psychological beings, interactions between them should be characterized by mutual respect as well as empathy and/or compassionate feelings. Humanistic proponents might be said to argue for "warm fuzzy doctors" ${ }^{16}$ I will argue that the type of humanism that is defended here is indeed rather weak. My main idea is that such a definition of humanism let's call it the compassionate or psychological approach to humanism - cannot be correct. Humanism cannot and should not be reduced to the ordinary nature of intersubjective encounters. ${ }^{17}$

\footnotetext{
${ }^{15}$ It should be noted that there is a whole movement in psychology called "humanistic psychology." This movement was introduced by Carl Rogers [43] and Abraham Maslow [44] and aims to emphasize the subjective individual and the importance of the self in psychology. Although this is beyond the scope of this paper, my argument against the compassionate use of humanism in narrative medicine and the phenomenology of medicine could probably be applied against the use of the concept of humanism in that movement. However, I see no reason to restrict medical humanism to what humanism means in that specific psychology movement. ${ }^{16}$ Despite Havi Carel insisting that warm fuzzy doctors is not what she is asking for, it is unclear how exactly she can avoid the criticism. "My revolt against the attitude towards illness that is common in the medical world is not a sentimental one. I am not suggesting that health professionals' precious time be wasted on feel-good chatting. [...] could some genuine care be introduced to the exchange?" [6, p. 49]

${ }^{17}$ At least it should justify the extraordinary importance of intersubjectivity, as Emmanuel Levinas and others, for instance, attempted to do. Quite ironically for the phenomenology of medicine, Levinas argued for the importance of intersubjectivity by showing the very limits of phenomenology and by turning to ethics.
} 
The main reason for wanting to move away from the compassionate approach to medical humanism is that it relies on a problematically narrow picture of medicine.

\section{A narrow definition of medicine}

Humanistic approaches all rely on a single focus of medicine: the patient-physician encounter. They worry that physicians fail to take into account the patient as a subjective psychological being in the practice of their science. I argue that narrowing medicine to the dyadic medical encounter is unnecessarily restrictive. The ideal of the patient-physician encounter is arguably driven by an individualistic view of science in which the physician/scientist possesses medical knowledge and makes it her art to apply it in particular situations. There is another possible picture of medicine, one which better draws on contemporary philosophy of science which views science as a social activity with multiple actors, human or non-human $[28,34,45,46]$ and more broadly on systems thinking. Such a definition of medicine includes all health services and institutions necessary for taking care of the patient, or in other words, any research, clinical, and organizational activities that have an impact on health. William Stempsey for example writes that beyond the clinical encounter, medicine is also "a kind of shorthand for "health care:"'

\footnotetext{
Medicine is the encounter of one who suffers from disease with one whose goal is to restore health. Yet the complexity of this encounter far exceeds its simple description. Medicine is sometimes taken broadly to include the work not only of physicians, but also of nurses, physical therapists, radiology technicians, and so on. In other words, "medicine" is a kind of shorthand for "health care." [47, p. 380]
}

More broadly, medicine may be understood as a country's health system. ${ }^{18}$ Moreover, health system, may be defined by both its health care services and its health insurance system. The financial basis of a health system - its health insurance system or lack thereof - indeed has a crucial impact on health and as such is a part of the services and institutions necessary for healthcare. Medicine doesn't only include health practitioners but health administration workers, institutions, the policies they enforce and the economic model it rests on. The World Health Organization gives a similar definition of health

\footnotetext{
${ }^{18}$ Health systems are indeed extremely different from one country to another.
} 
systems as "any activities (people or actions) which aim to promote, restore or sustain health" [48]. The question of the definition of medicine is indeed closely related to that of its aim. What is the aim of medicine ? $^{19}$

Proponents of humanistic medicine usually write that the goal of medicine is humanitarian because it consists of alleviating suffering and taking care of the individual patient's welfare. However, although it is true that welfare may be understood at an individual level, it can also be understood from a populational perspective. If the goal of medicine was understood broadly it would amount to alleviating suffering in the population and increasing its general welfare, or in a utilitarian vein, medicine's goal would be to maximize the amount of welfare in a society and treat suffering resulting from illnesses as much possible. The question of course is, should medicine's goal be public health or individual health or both? I take it that including public health in the definition of the aim of medicine is not controversial, although the current philosophy of medicine has not debated or lingered on it so far. One can go beyond the narrow picture of medicine taken up by humanistic proponents. To summarize, medicine's definition does not have to be restricted to the patientphysician encounter and may instead include the whole healthcare system's activity. What's more, the aim of medicine doesn't have to be restricted to the health of one individual patient but may also include public health. The argument here is both philosophical and naturalistic: ${ }^{20}$ in today's western societies, medicine is inseparable in practice from healthcare, as individual health is inseparable from public health.

Unsurprisingly, humanistic approaches' narrow picture of medicine goes together with their compassionate and intersubjective understanding of humanism: the ideal picture of the patientphysician relationship is the consequence of a narrow individualistic view of science and medicine, and the meaning of humanism in turn is restricted by the ideal picture of the patient-physician

\footnotetext{
${ }^{19}$ This question can be understood in different ways. Whether medicine's aim is to treat illness or promote health is not directly pertinent to my argument so I will not address it here.

${ }^{20}$ I refer to the naturalistic trend in the philosophy of science according to which, briefly speaking, science is what scientists do.
} 
relationship. Does broadening the picture of medicine and its goal to include the health system and public health end up clashing with humanistic ideals? I will precisely argue the opposite: broadening the picture of medicine beyond the patient-physician relationship should help to revisit humanism beyond a compassionate and psychological approach. The question is twofold. First, can a health system or a health policy be compassionate and/or tailored down to the needs of individual patients? Secondly, can a broader approach to humanism follow from a broader understanding of medicine and its aim?

\section{Public health and health policies: a better framework for humanism}

\subsection{The advantages of the public health approach}

One may first think that including public health in the definition of medicine moves the medical model farther from the ideals of current proponents of humanistic medicine. Indeed, their understanding of humanism - which values the subjective psychological states of the individual over anything else - may seem to clash with the aim of public health, which does not focus on the individual but on populations. Yet because public health promotes prevention and because it analyzes health determinants in different populations, it does not, for instance, reduce patients to their biological body. Remember that the reduction of the patient to her physical body is one of the leitmotifs of humanistic approaches against the biomedical model. Instead, the public health approach is largely "biopsychosocial" [17] because it places individuals in their economic, social, and cultural environments, in order to understand health determinants and health inequalities. Despite humanistic proponents systematically referring to George Engel's biopsychosocial model [3, p. 393, 10 , p. 222,13, p. 223,40, p. 17], they almost never mention distinctive social and cultural questions. For instance, in Havi Carel's 2006 book, the chapter devoted to "social" questions covers interaction with family and friends. Such an approach is intersubjective, psychological - admittedly important but not distinctively social and as such insufficient. The public health approach, by focusing notably 
on health inequalities and contrary to the current humanistic approach, seem to be able to take the social aspect of medicine at face value. ${ }^{21}$

Another disadvantage of an individualistic view of medicine is the weight that is consequently put on individual practitioners' shoulders. For instance, Rita Charon is too quick to make the physician a multitask helper: a psychologist, a therapist, a social worker, and even a friend. To illustrate the importance of narrative skills, she tells the story of several patients who turned out to have social or psychological problems and how she took care of these. She notably recalls giving psychotherapy to one of her patients for several weeks despite not being a therapist or a psychiatrist. About a grieving patient, she writes that

[she] will see her next week, and the week after that, not to fix anything but simply to watch with her, to listen to her, to behold, in awe, her faith and power and love. [2, p. 11]

Viewing general doctors as multitask helpers is problematic mostly because it makes medical practice rely on the good will of each practitioner - practitioners who will often be lacking the necessary training and competences (or simply lacking the will). Health policies and collective work, less sensitive to individual will, may have a larger impact than the practice of one physician. Looking at a few examples of medical policies might help broaden the question of humanism in medicine: how exactly can a policy be humanistic, and in what sense?

\subsection{An example of policy: French Cancer plans}

\subsubsection{Supportive care}

The successive "Cancer plans" set up in France since 2003 have led or have tried to lead to what may be called "patient-centered" care in oncology: notably they led to the diffusion of what we call supportive care for cancer patients. Supportive care is legally defined as the necessary care and support for sick patients on top of their surgical, chemotherapeutic and/or radiation treatment.

\footnotetext{
${ }^{21}$ I don't need to defend Engel's biopsychosocial here. It is enough to show that public health - albeit being a scientific approach that relies on statistics and the study of populations - does not reduce patients to their physical bodies. It also illustrates that only focusing on the patients as individual psychological beings is insufficient even on humanistic approaches' own terms as it clashes with their social environment.
} 
Supportive care deals primarily with palliative care, i.e. the management of pain, tiredness, nutritional problems, digestive and respiratory problems. It also deals, for instance, with body-image issues (e.g. how to deal with hair loss) and social issues. Different people such as nutritionists, psychiatrists and beauticians and social workers may participate in such supportive care. The explicit objective of supportive care is to provide a better quality of life for patients by implementing a holistic approach to patient care in order to deal with physical, psychological, and social issues. Although the implementation is far from being perfect, it allows, for instance, the cost of a beautician's appointment and/or a wig to be partly taken care off by national health insurance. This example points out the limitations of an individualistic view of medicine focused solely on the physician: team and interdisciplinary work should not be overshadowed by the ideal of the patientphysician relationship. The importance of institutional, legal, and financial actors necessary to implement such care should also be mentioned. It is crucial to emphasize that actors in medicine may be human but also institutional: for instance, French cancer plans were the impulse for the creation in 2005 of a body called the French National Institute for Cancer (FNIC). The FNIC is interesting because it includes all aspects of cancer care, research and patient advocacy in one body, enabling it to monitor the success and failure of the successive plans [49]. ${ }^{22}$ Patient-centered, holistic care, and even we will see in my next example, possibly compassionate care, do not have to be restricted to the good will of one physician - and probably shouldn't be, if one expects them to be efficient and available to all.

\subsubsection{Temporary authorization for use of new experimental cancer drugs}

The cancer plans also led to the decision that there will be no rationing of new cancer drugs in France. In other words, most new cancer drugs are quickly made available to cancer patients that might benefit from them. Making it available means not having to wait for market authorization but it also means that the national health insurance reimburses it. For example, in 2005 the new drug

\footnotetext{
${ }^{22}$ The Institute is unique in French health policy. It is distinct from the government and open to private sector organizations, for example, professional and patient associations, as well as to health insurance funds.
} 
Herceptin (trastuzumab) was made available through a temporary protocol only five months after the successful trials conducted in the United States. ${ }^{23}$ It was made possible thanks to the negotiations of the FNIC with relevant health authorities [49, p. 649]. This is what we usually call a "compassionate use of drugs"; or in the case of France a "temporary authorization for use." Not rationing new experimental treatments is of course a choice. Here it is a political choice in the shape of a health policy. Is it a compassionate choice? This is not clear, although it seems to be a humanistic choice, in the sense that it focuses on a moral value, justice. One cancer drug was indeed made available to all, and not just to those who could afford it. Yet the choice was not made by an individual caring about one patient but a political and normative choice enabled by various complex institutional and operational work and legal negotiations. It is also a choice that tends to follow the most recent scientific research, illustrating how humanism doesn't have to work against science or the biomedical model. The reasons behind such a political choice are far too complex to list but they are different from the reasons found in the empathetic process in a patient-practitioner relationship. Such a decision and the negotiations enabling it can have a crucial impact on a person's life - indeed life or death. Thus, they are a distinctive part of medicine, and they must be taken into account in a humanistic medicine approach. It should, however, be noted that such a decision will always have to be an economical compromise: indeed, valuing justice also means that resources should not be monopolized by one group of patients. For instance, Australia decided at first that the reimbursement of Herceptin was not cost-effective and refused to include it in its Pharmaceutical Benefits Scheme $[50$, p. 3689$] .{ }^{24}$ However, under intense public pressure (led, for instance, by the Breast Cancer Network Australia), the Australian government finally decided to create a separate taxpayer-funded Herceptin Program. Since then, several reports have investigated the challenge of affordable and timely access to cancer medicines in Australia compared to other OCDE countries. ${ }^{25}$ The question is

\footnotetext{
${ }^{23}$ Herceptin is used to treat breast cancer.

${ }^{24}$ The PBS provides subsidies prescription drugs to residents of Australia.

${ }^{25}$ See $[51,52]$.
} 
thus not only normative but also operational: should we give equal access to a drug? How should we take the decision? And how long should it take us?

Current humanistic approaches usually don't connect humanism to a broader ethical and political project. For instance, when Charon talks about a "more ethical" care [2, p. 7], she doesn't specify in what sense care must be more ethical and how narration increases the ethical dimension of care. Such topics as consent, autonomy, and justice are not mentioned. My argument is twofold: First we should apply humanism to health systems as well as to the dyadic medical encounter. Secondly, applying humanism to health systems necessarily raises fresh ethical as well as political questions, regarding specifically justice and equality. A type of humanism that prompts ethical and political questions, therefore a broader type of humanism, is not unheard of, in philosophy and elsewhere. Humanism can be understood as a broad spectrum of values and beliefs that is not restricted to an individual-centered or psychological-centered approach. ${ }^{26}$ For instance, moral humanism defends the respect of the fundamental rights of human beings and takes justice as a foundation. Such a view of humanism finds its roots in the French Enlightenment: at that time, liberal and social reformers believed that virtue could be defined by human reason alone and that belief came together with the defense of progressive social reforms. ${ }^{27}$

European health systems are sometimes described, from a foreign perspective, as "generous." It is especially "generous" in the case of cancer drugs, some would say, because they are extremely expensive treatments. Yet "generosity" and "compassion" seem to imply that the action is somewhat neither an ethical nor legal imperative: it seems to go beyond what is necessary. Unnecessary actions would even seem to be in a way unjustified - and unjust. Therefore, I think it's

\footnotetext{
${ }^{26}$ In fact, individual-centered approaches are traditionally suspicious from a humanistic point of view. For instance, Jean-Paul Sartre's existentialism (and subjectivist approach) was strongly criticized by tenants of humanism. His famous short book, L'existentialisme est un humanisme was written precisely to address their attack [53].

${ }^{27}$ This reformist and progressive view of humanism can be credited to Pierre-Joseph Proudhon and later thinkers such as John Dewey, Charles Francis Potter, William James, Karl Jaspers or Maurice Merleau-Ponty.
} 
better to look at those health systems, not as generous but as humanistic. For some countries, healthcare is not a product, a technique or a gift but is considered as a right enshrined in the law. For instance, in France, health has been a constitutional and human right since 1946 and 1952 and the building of what we call "social security." Saying that health is a right means that one can expect to be in her best possible health state, i.e. she can expect to live in a safe environment and to access healthcare services when needed. According to the current French public health code, patients should receive the best care and treatment possible [54]. This is why temporary protocols to use new experimental drugs are not called "compassionate use of drugs," they are not the results of compassion but are technical administrative devices forged in order to respect the law, ${ }^{28}$ which is based on the belief that the best treatments possible shouldn't be rationed or delayed. ${ }^{29}$

\section{Revising humanism in an outcomes-oriented humanistic medicine}

\subsection{A comparison: humanistic physicians versus humanistic health systems}

Before turning to the defense of my approach, it is useful to compare in detail the humanistic approach I have just criticized and the approach I wish to defend. The current approach defends the idea of humanistic or humane physicians and practitioners while my approach defends the idea of humanistic health systems. If one prefers, "device" or "plan of action" can be used over "system." A system shouldn't be misunderstood for an uncaring and uncontrollable process. Health policies, administrations, and the like are not occult actors and can be submitted to intention. Whether it focuses on physicians or systems, humanistic medicine addresses three issues: the definition of the goal of medicine, the conditions of possibility of such a goal and the prominent values behind that goal.

\footnotetext{
${ }^{28}$ Compare this to the polemical compassionate use of drugs in the recent Ebola pandemic, where preexperimental drugs were given in and out of clinical studies $[55,56]$. In these cases, drugs were given not because they were the best drugs available but because no other drugs were available. Here "compassion" is taken in a strong emotional sense.

${ }^{29}$ It goes without saying that the " best " treatments are decided by physicians upon scientific data and not by lawmakers. Furthermore, there are obviously limits on the resources that need to be compromised with.
} 
In the case of the humanistic physician's approach, the goal of medicine is taken to be the best care possible for the patient - including emotional, existential and psychological care. The conditions of possibility of such a goal are the good will of the physician, her time, ${ }^{30}$ her intuitive and/or professional talents, and an overall good relationship. The prominent values that support this kind of humanistic medicine are among others, autonomy, freedom, compassion, empathy, and respect.

On the approach I defend, however, the goal of humanistic devices is not the best care for the individual patient, but the best care possible for all. The conditions of possibility of such a goal are an historical and ongoing design of the medical device with the possibility of top-down and bottom-up initiatives (i.e., a national health system, including the financial aspects). The prominent humanistic values of such an approach are justice, access, public health, and human rights.

Both approaches may of course be closely intertwined. For instance, the health system approach does not necessarily contradict a patient-centered approach; it can try to implement it. Conversely, the good will of a physician is also important when orienting a patient through the possibility of the administrative device: introducing the patient to supportive care for instance. By comparison, saying that there is such a thing as a legal system - with administrative and other factors impacting or guiding that system - doesn't lead to rejecting or ignoring the protection of each individual's rights in that system. Consequently, I do not want to state that one should choose between a patient-physician relationship approach and an outcomes-oriented or health system approach. However, for the same reasons, I do not want to say that the approach I wish to defend is there to complement current humanistic approaches. This is not contradictory, because the opposite would mean embracing the distorted views of science and intersubjectivity found in the current humanistic approaches. Furthermore, since one of my claims is that the intersubjective nature of the clinical encounter depends heavily on structural and policy-based decisions, or briefly, that it cannot

\footnotetext{
${ }^{30}$ However, Rita Charon argues that narrative skills allow physicians to work faster.
} 
be separated from the whole of medicine, my approach does not aim to be a complement either. Rather, my approach absorbs and transforms the question of intersubjectivity and the physicianpatient relationship in medicine. This absorption could then lead to an approach dealing with the physician-patient relationship outside mischaracterizations of medicine and science. For instance, it would take into account the impact of external factors on the behavior of a health professional. ${ }^{31}$ This approach is yet to be done and out of this paper's scope. In what follows, I introduce in more detail the approach I wish to defend, which I call an outcomes-oriented approach to humanistic medicine.

\subsection{An outcomes-oriented humanistic medicine}

The particularity of my approach is first that it doesn't set itself against the biomedical model, naturalism, or science, nor does it distinguish a medical art from a scientific medicine. Indeed, both philosophical moves are disputable from a point of view of contemporary philosophy of science. On this view, if there is such a thing as dehumanization in medicine, my approach will not look for it in the defects of the biomedical model as such, whether it means science or naturalism, but in one particular health system or part of that health system. Biomedical aspects of medicine (say, for instance, blood testing) will not be considered as dehumanizing prima facie. ${ }^{32}$ Furthermore, instead of relying on an individualistic understanding of both medicine and humanism, my approach relies instead on a broad definition of medicine: health systems. On both counts, I chose to rely on an upto-date philosophy of science - a naturalistic and social philosophy of science which views science as a social and normative activity with multiple actors. On such a view, actions and actors of a health system are a distinctive part of medicine and they cannot be ignored by the philosophy of medicine. The disparity between health systems in otherwise rich countries helps to illustrate how important the differences in the design of (or lack of) a health system are, not only for public health but also for

\footnotetext{
${ }^{31}$ It should be noted that ethics has already provided extensive analysis about how the clinical encounter should and should not occur.

${ }^{32}$ The conditions and consequences of said blood testing in a particular situation could, however, be studied.
} 
individual patients. ${ }^{33}$ Furthermore, as shown in section 6.1 , including public health in that approach means that it will include biological as well as psychosocial factors, thus avoiding a caricatural view of science. Finally, since the designs of health systems are the consequences of political choices, I think it's not possible to discuss "humanizing" medicine without bringing into the discussion deeply normative ethical and political problems such as health inequalities, justice and access.

Phenomenological and narrative approaches to medicine - two prominent humanistic approaches - ask a radical question about medicine: "what is a good medicine ?" $^{34}$ They worry that biomedicine is not good enough because it doesn't accommodate patients' experience and emotional, existential needs. Interestingly, they often talk about good doctors but almost never talk about a good medicine. They seem to think that the scientific or "biomedical" question is settled and they proceed to study the relationship between patients and physicians and how to improve it. However, there is a whole complex world in between. What will the best technical medical procedure be good for if it's not accessible? What will the best and most compassionate doctor be good for if she's not accessible or if she can't prescribe life-saving drugs? Those are crucial questions. Medicine is not a product to be delivered in a physician-patient relationship that has to be improved; it is a complex interaction of actors (human, financial, administrative and economic actors) that determines the possibility and the modality of the patient-physician encounter and its outcomes. The important question is: what are good conditions of the medical encounter and how can we improve them? What is at stake, therefore, is not the intersubjective quality of the clinical encounter but the performance of the overall structure of medicine that precedes it. In other words, the approach I defend is outcomes-oriented in the sense that it focuses on the outcomes and the performance of the health system, that is, on its capacity to answer crucial questions about the possibility and modality of healthcare. Ultimately, the capacity for a health system to produce good health outcomes

\footnotetext{
${ }^{33}$ See WHO report on the performance of health systems [48].

${ }^{34}$ Of course, defining what a good doctor or a good medicine should be is ambiguous ("good" as in "efficient" or "good" as in "morally good"?). It seems that a morally good doctor should be as efficient as possible, but I will leave this question aside for now.
} 
is what matter. Insisting on the outcomes of one system also means that one must focus on the operational devices one system has implemented in order to run that system and how it plans to provide the best care for all (if indeed it does plan to do so). It thus allows us to ask bluntly: if a system doesn't aim to provide the best care for all, in what sense left can it be genuinely humanistic and in what sense can it provide the "best" of medicine? In fact, it is only by making my approach outcomes-oriented that it becomes distinctively and radically humanistic. It does so because it introduces the goal of access to medicine on top of the quality of that access. Access is indeed the condition of possibility of any medical outcomes and thus becomes the foundation of any humanistic approach to medicine. The questions of access, justice, and health inequalities, all closely related, are highly ethical and political questions that shape a moral humanism that goes beyond the current compassionate or psychological approach to humanism. Furthermore, shifting away from an individual-centered approach to humanism is key in developing a type of humanism more faithful to the name. Examples in section 6.6.1. and 6.6.2. have illustrated how crucial it is to look at specific system devices in order to understand what it means for medicine to be humanistic or not. ${ }^{35}$

\section{Conclusion: from physicians to health devices, a priority shift for humanistic medicine}

There are several flaws in some of the current humanistic approaches to medicine and notably in the phenomenology of medicine and narrative medicine. Covering all these flaws was not the topic of this paper, although one problem was worth noting: both narrative medicine and phenomenology of medicine make their case against the biomedical model by respectively relying on an outdated view of science and a caricatural definition of naturalism. This flaw is relevant here because it should be clear now that it leads humanistic proponents into endorsing narrow definitions of both medicine and humanism. While medicine has been reduced to the patient-physician relationship, humanism

\footnotetext{
${ }^{35}$ Examples have also shown that health systems are constantly built on difficult compromises and difficult decisions. It also should be noted that patient-centered care is one type of humanistic approach that have been successfully implemented in France and elsewhere. They can both emerge from local initiatives or from higher impulses.
} 
has been reduced to a psychological and compassionate approach. Both definitions are lacking and should be expanded.

From a broader definition of medicine, which include health systems, health policies, and other relevant actors in that system, we can shift to a more radical and normative sense of humanism. The approach I defend does not focus on the patient-physician relationship but on the conditions of that relationship, that is on the health system and its multiple devices (administrative, legal, financial, etc.). Such topics as access and justice are therefore given a central place in the discussion. If the intersubjective approach in general needs not be dismissed altogether, it can be absorbed, so to speak, by my approach. A priority shift is needed in favor of a less individual-centered approach, if one's goal is indeed to "humanize" medicine. My aim in this paper was to give the first impulse for a new framework for humanism and medicine to introduce aspects of medicine which currently go unnoticed in the literature. Further discussion will of course be required to explore these aspects. ${ }^{36}$

\section{References:}

[1] Charon R. Narrative medicine: a model for empathy, reflection, profession, and trust. Jama 2001; 286:1897-1902.

[2] Charon R. Narrative medicine: honoring the stories of illness. Oxford; New York: Oxford University Press; 2006.

[3] Hunter KM. Doctors' Stories: The Narrative Structure of Medical Knowledge.1991.

[4] Svenaeus F. The Hermeneutics of Medicine and the Phenomenology of Health: Steps Towards a Philosophy of Medical Practice. Kluwer Academic Publishers; 2000.

[5] Svenaeus F. The Phenomenology of Falling III: An Explication, Critique and Improvement of Sartre's Theory of Embodiment and Alienation. Hum Stud 2009; 32:53-66.

[6] Carel H. Illness: The Cry of the Flesh. Acumen; 2008.

[7] Carel H. Phenomenology and its Application in Medicine. Theoretical Medicine and Bioethics 2011; 32:33-46.

[8] Carel H. Phenomenology as a Resource for Patients. Journal of Medicine and Philosophy 2012; 37:96-113.

[9] Toombs SK. The Meaning of Illness: A Phenomenological Approach to the Patient-Physician Relationship. Journal of Medicine and Philosophy 1987; 12:219-240.

[10] Toombs SK. Illness and the Paradigm of Lived Body. Theoretical Medicine and Bioethics 1988; 9.

\footnotetext{
${ }^{36}$ I thank anonymous reviewers for their comments. I also thank all participants of the workshop "Medical knowledge in a social world" which was held at the University of Irvine in 2016 for their helpful comments and encouragements. Special thanks also go to Guillaume Didier and James Angove for proof-reading this paper.
} 
[11] Toombs SK. Handbook of Phenomenology and Medicine. Kluwer; 2001.

[12] Toombs SK. The Role of Empathy in Clinical Practice. Journal of Consciousness Studies 2001; 8:57.

[13] Marcum JA. Reflections on Humanizing Biomedicine. Perspectives in Biology and Medicine 2008; 51:392-405.

[14] Solomon M. Making Medical Knowledge. Oxford University Press; 2015.

[15] Cassell EJ. The Nature of Suffering and the Goals of Medicine, 2nd Edition. New York: Oxford University Press; 2004.

[16] Cassell EJ. The Healer's Art. Cambridge, Mass: The MIT Press; 1985.

[17] Engel GL. The need for a new medical model: a challenge for biomedicine. Science 1977; 196:129-36.

[18] Halpern J. From Detached Concern to Empathy: Humanizing Medical Practice. OUP USA; 2001.

[19] Sulmasy DP. A biopsychosocial-spiritual model for the care of patients at the end of life. Gerontologist 2002; 42 Spec No 3:24-33.

[20] Khushf G. An Agenda for Future Debate on Concepts of Health and Disease. Medicine, Health Care and Philosophy 2007; 10:19-27.

[21] Lemoine M. Defining disease beyond conceptual analysis: an analysis of conceptual analysis in philosophy of medicine. Theoretical Medicine Bioethics 2013; 34:309-25.

[22] Marcum JA. An Introductory Philosophy of Medicine: Humanizing Modern Medicine. 2008 edition. Dordrecht: Springer; 2008.

[23] Svenaeus F. Hermeneutics of Medicine in the Wake of Gadamer: the Issue of Phronesis. Theoretical Medicine and Bioethics 2003; 24:407-31.

[24] Taylor C, Carnevale FA, Weinstock DM. Toward a Hermeneutical Conception of Medicine: A Conversation with Charles Taylor. J Med Philos 2011; 36:436-45.

[25] Schramme T, Edwards S. Handbook of the Philosophy of Medicine. Springer Netherlands; 2017.

[26] Solomon M, Kincaid H, Simon J. The Routledge Companion to Philosophy of Medicine. Routledge; 2017.

[27] Vannatta S, Vannatta J. Functional Realism: A Defense of Narrative Medicine. Journal of Medicine and Philosophy 2013; 38:32-49.

[28] Longino HE. Science as Social Knowledge: Values and Objectivity in Scientific Inquiry. Princeton, N.J: Princeton University Press; 1990.

[29] Longino HE. The Fate of Knowledge. Princeton, N.J: Princeton University Press; 2001.

[30] Wylie A. Thinking from Things: Essays in the Philosophy of Archaeology. Berkeley: University of California Press; 2002.

[31] Khanom A, Wright S, Rapport F, Doel M, Clement C, Storey M. "Lives at Risk" Study: Philosophical and Ethical Implications of Using Narrative Inquiry in Health Services Research. In: Schramme T, Edwards S, editors. Handbook of the Philosophy of Medicine, Springer Netherlands; 2015.

[32] Lemoine M. La désunité de la médecine: Essai sur les valeurs explicatives de la science médicale. Paris: Hermann; 2011.

[33] Dupré J. The Disunity of Science. Mind 1983; 92:321-46.

[34] Solomon M. Social empiricism. Cambridge, Mass.: MIT Press; 2001.

[35] Kuhn TS. The Structure of Scientific Revolutions. Chicago, IL: University of Chicago Press; 1962.

[36] Kuhn TS. The Essential Tension: Selected Studies in Scientific Tradition and Change. Revised ed. edition. Chicago: University Of Chicago Press; 1977.

[37] Hess HH. History of ocean basins. Petrologic Studies 1962; 4:599-620.

[38] De Caro M, Macarthur D. Naturalism and Normativity. New York: Columbia University Press; 2010.

[39] Sholl J. Putting phenomenology in its place: some limits of a phenomenology of medicine. Theoretical Medicine Bioethics 2015; 36:391-410.

[40] Svenaeus F. Naturalistic and Phenomenological Theories of Health: Distinctions and 
Connections. Royal Institute of Philosophy Supplements 2013; 72:221-238.

[41] Boorse C. On the Distinction between Disease and Illness. Philosophy \& Public Affairs 1975; 5:49-68.

[42] Giroux É. Après Canguilhem : définir la santé et la maladie. Paris: Presses Universitaires de France - PUF; 2010.

[43] Rogers C. Client Centred Therapy: Its Current Practice, Implications and Theory. London: Constable; 1951.

[44] Maslow AH. Notes on Being-Psychology. Journal of Humanistic Psychology 1962; 2:47-71.

[45] Hull DL. Science as a Process: An Evolutionary Account of the Social and Conceptual Development of Science. Chicago: University Of Chicago Press; 1988.

[46] Thagard P. Conceptual Revolutions. New Ed edition. Princeton University Press; 1993.

[47] Stempsey WE. Philosophy of Medicine Is What Philosophers of Medicine Do. Perspectives in Biology and Medicine 2008; 51:379-91.

[48] WHO. WHO | Health systems: improving performance. WHO 2000. http://www.who.int/whr/2000/en/ (accessed June 3, 2016).

[49] Khayat D, Kerr D. A new model for cancer research in France. Nat Rev Cancer 2006; 6:645-51.

[50] Pearson S-A, Ringland CL, Ward RL. Trastuzumab and metastatic breast cancer: trastuzumab use in Australia--monitoring the effect of an expensive medicine access program. J Clin Oncol 2007; 25:3688-93.

[51] Medicines Australia Oncology Industry Taskforce. Access to cancer medicines in Australia 2013.

[52] Wonder M. Reimbursement success rates and timelines for new medicines for cancer; an international comparison 2014.

[53] Sartre J-P, Elkaïm-Sartre A, Cohen-Solal A. Existentialism Is a Humanism. Trade Paperback Edition edition. New Haven: Yale University Press; 2007.

[54] Code de la santé publique - Article L1110-1-1. vol. L1110-1-1. n.d.

[55] Folayan M, Brown B, Yakubu A, Peterson K, Haire B. Compassionate use of experimental drugs in the Ebola outbreak. The Lancet 2014; 384:1843-4.

[56] Rid A, Emanuel EJ. Compassionate use of experimental drugs in the Ebola outbreak - Authors' reply. The Lancet 2014; 384:1844. 